\title{
Conteúdos e identidade cultural na sociedade da informação
}

\author{
Antonio Miranda* \\ Departamento de Ciencia de la Información y D ocumentación \\ Universidade de Brasília, Brasilia, Brasil \\ Teléfono (561)3482422; \\ Fax 2738454
}

\section{RESUMEN}

Se analizan los escenarios y tendencias de la sociedad de la información en el Brasil, que requieren la implantación de una sólida plataforma de comunicaciones que permitan beneficios sociales, lo que requiere del fortalecimiento de una infraestructura (escuelas, bibliotecas, laboratorios). Se trata de preparar para el futuro a una nueva generación de brasileños. Se examinan también las posibles implicaciones de la sociedad de la información (Internet, servicios de información, contenidos) previendo que tendrán una importante determinación en el desarrollo económico, social y en la calidad de vida de sus habitantes. También reflexiona el autor sobre los contenidos de la información y el impacto que éstos pueden tener sobre la identidad cultural de sus habitantes (sujeto postmoderno; identificación de un proceso más que identidad plena entre los individuos; proceso de globalización y sus repercusiones).

Palabras clave: Sociedad de la información; Identidad cultural; Brasil.

\section{CULTURAL CONTENT AND IDENTITY IN THE INFORMATION SOCIETY}

Antonio Miranda
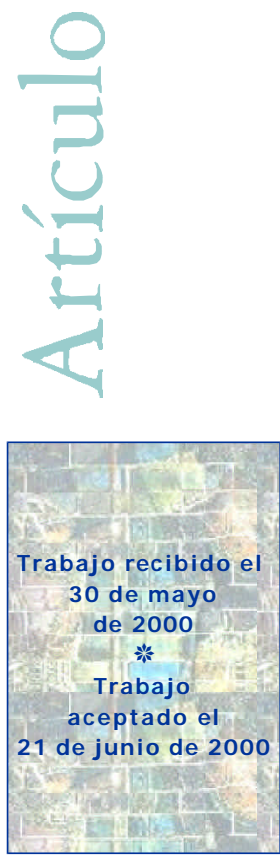

\begin{abstract}
ABST RACT
The tendencies and present conditions of the information society in Bra zil are analyzed, resulting in the conclusion that a solid communications platform, that will allow social benefits, is required. In turn, this platform requires a strengthening of the infrastructure (schools, libraries,
\end{abstract}

* Membros do Grupo de Trabajo sobre Contenidos e Identidad Cultural: Antonio L. C. Miranda (Universidade de Brasília); Abel Packer (D irector de Bireme); Abigail de O liveira Carvalho (Universidade Federal de Minas G erais): Aldo de Albuquerque Barreto (CNPq/ Ibict); Fernando Flávio Pacheco (PUC/ PR); José Marques de Mello (Universidade de São Paulo); José Teixeira Coelho Netto (diretor Museu de Arte Contemporânea de São Paulo); Nelson de Castro Senra (Instituto Brasileiro de G eografia eEstatítica); O thon Jambeiro (vice-reitor Universidade Federal da Bahia) e Yones Sepulveda Chastine (coordinadora del banco de datos Prossiga).

Más informaciones sobre la SO CINFO de Brasil en: www.socinfo.org.br 
laboratories), in the interest of preparing a new generation of Brazilians. Also approached are the possible implications of the information society (the Internet, information services, contents) on the economic and social development of the inhabitants- as well as quality of life issues. The author reflects on informational contents and the effects these might have upon the cultural identity of the inhabitants.

Key Words: Information Society; Cultural Identity; Brazil.

\section{SOCIEDADE DA INFORMAÇÃO: CENÁRIOS E TENDÊNCIAS}

O

Programa Sociedade da Informação, resultante de trabalho iniciado em 1996, pelo Conselho Nacional deCiência eTecnologia, tem como finalidade substantiva lançar os alicerces de um projeto estratégico, de amplitude nacional, para integrar e coordenar o desenvolvimento e a utilização de serviços avançados de computação, comunicação e informação, e de suas aplicações na sociedade, de forma a alavancar a pesquisa e a educação, bem como assegurar que a economia brasileira tenha condições de competir no mercado mundial.

Um elemento essencial para a construção da Sociedade da Informação no Brasil é a implantação de uma sólida plataforma de telecomunicações, na qual possam difundir-se e florescer as aplicações em áreas de alto conteúdo e retorno social, como educação, saúde, meio-ambiente, agricultura, indústria e comércio. Requer a instalação e o fortalecimento de adequadainfra-estrutura de escolas, bibliotecas elaboratórios, a fim de que uma nova geração de brasileiros se prepare para o futuro.

Elementos estruturais - como sejam a informática nas suas dimensões de harde de software, a estrutura de telecomunicações, enquanto rede interligada nacional e internacionalmente; a indústria de equipamentos eletro-eletrônicos; e os serviços de comunicações e informações, particularmente os informativo e culturais (internet, museus, arquivos, bibliotecas, editoração eletrônica evirtual, publicidade, imprensa, radio, cinema e TV) - requerem análises em perspectiva. Implica numa reflexão, a um só tempo, sobre a aspiração de modernidade pretendida pelo Programa Sociedade da Informação quanto sobre a realidade objetiva so bre as relações entre os grupos de interesse nacionais e internacionais, governos e pessoas.

0 cenário em que estas relações e os elementos estruturais da Sociedade da Informação estão operando, comporta três tendências interrelacionadas:

I.integração vertical, estimulada por desregulação e competição, num crescente mercado mundial, interligando num mesmo conglomerado desde corporações internacionais até empresas locais; II.globalização do mercado da produção intelectual, com produtos simbólicos marcados por um caráter crescemente internacional; e 
III.privatização, caracterizada pela predominância de interesses privados - em detrimento, muitas vezes, do interesse público - controlando as empresas e instituições na área das comunicações e da informação.

A primeira tendência, a de integração vertical, é facilmente comprovável, porque as empresas que operam no Setor de Informação e Comunicações são objeto de transações de compra e venda como quaisquer outras empresas comerciais ou industriais. Independentemente de leis e normas governamentais, ou mesmo estimuladas por elas, um mercado mundial de firmas operando no setor foi estabelecido ea propriedade concomitante de variadas e numerosas empresas tomou-se uma comum e normal situação. Em decorrência, um crescente grau de integração de propriedade entre aquelas indústrias está rapidamente emergindo, particularmente com relação a jornais, revistas, livros, provedores de Internet, concessionárias de telefonia e transmissão de dados, companhias fonográficas e cinematográficas, TV aberta, à cabo e via satélite. Este fenômeno tem provocado muitos realinhamentos organizacionais, com grandes e multifacetados complexos de serviços informativo-culturais fundindo-se entre si.

Q uanto à segunda tendência, a da globalização do mercado da produção intelectual, pode-se arguir que, dentro do quadro de mudanças estruturais porque vem passando o mundo, a disseminação de padrões culturais globalizados vem assumindo proporções sem limite. Tal situação tem se acentuado principalmente porque 0 modo de produção industrial capitalista tornou-se hegemônico na produção e distribuição de produtos intelectuais, e através de seus mecanismo de distribuição - os mídia em geral - interfere poderosamente nos processos econômicos, políticos e culturais das sociedades nacionais. Enquanto processo de desenvolvimento de complexas interconexões entre sociedades, culturas, instituições e indivíduos, aglobalização estimula e favorece a remoção dos nossos relacionamentos e de nossas referências de vida de contextos locais para contextos transnacionais.

No que se refere à privatização, pode-se afirmar, em primeiro lugar, que o desequilíbrio mundial da riqueza, associado à crescente imprescindibilidade da informação para os processos produtivos e a geração de empregos, tem fortalecido a posição das empresas. Nos dias de hoje, o acesso a avançados serviços de informação e a equipamentos de informática e de telecomunicações de última geração tem vitais implicações econômicas para o desenvolvimento do país como um todo. Por esta razão muitos países têm estabelecido políticas para o favorecimento e estímulo à produção desses serviços e equipamentos.

Ademais, a informação, as telecomunicações, os mídia, a informática e a indústria eletro-eletrônica passaram a ocupar um lugar central no processo de acumulação de capital. 0 efeito imediato disto foi a revisão das leis, decretos e regulamentos que normalizam o setor. A isto se deu o nome de desregulamentação ou re-regulamentação. Sob ainfluência desta - e da privatização que lhe dá conseqüência -, com considerável assistência dos estados nacionais, a tecnologia aprofundou eestendeu a habilidade das empresas para tornar mercadorias os produtos da telemática - que são informação em 
todas as suas formas. Na síntese imediamente posterior, a informação e suas tecnologias eliminaram os empecilhos que impediam o capital de expandir-se territorial e funcionalmente, sem risco de perder o controle central do processo.

Fator altamente significativo neste cenário é o desenvolvimento científico e tecnológico vertiginoso da informática, das telecomunicações e da eletrônica. Isto está provocando uma explosão mundial das comunicações via cabo, microondas e satélites, e de equipamentos de multimídia, os quais podem aperfeiçoar as possibilidades de 0 consumidor escolher, acessar e usar incontáveis e multifacetados serviços informativo-culturais. Se os anos 90 formam a década da internacionalização das comunicações em rede, aumentando o uso da telefonia e serviços a ela ligados, os primeiros anos do terceiro milênio deverão consolidar a indústria da informática e os serviços de informação, associados 'as telecomunicações, como um dos principais motores - ou mesmo o principal motor - do desenvolvimento econômico, social e cultural.

Um aspecto importante a ser evidenciado é o fato de o fenômeno da conglomeração nos setores de informática, eletro-eletrônica, serviços informativo-culturais e telecomunicações, impulsionado pela dinâmica e racionalidade da economia capitalista internacional, estar levando as corporações a interconectarem tecnologias, cujos limites de convergência não podem ser ainda previstos. Esta é uma das razões pelas quais a estrutura das indústrias e serviços de informação, eletrônica e comunicações - e seu status legal einstitucional nas políticas públicas - tem estado em acelerado processo de mudança.

A convergência tecnológica vem eliminando os limites entre os meios, tornando-os solidários em termos operacionais, e erodindo as tradicionais relações que mantinham entre si e com seus usuários. Na verdade, com a tecnologia digital torna-se possível o uso de uma linguagem comum: um filme, uma chamada telefônica, uma carta, uma artigo de revista, qualquer deles pode ser transformado em dígitos e distribuído por fios telefônicos, microondas, satélites ou ainda por via de um meio físico de gravação, como uma fita magnética ou um disco. Além disso, com a digitalização o conteúdo torna-se totalmente plástico, isto é, qualquer mensagem, som, ou imagem pode ser editada, mudando de qualquer coisa para qualquer coisa.

A convergência tecnológica parece tender a cancelar a validade de fronteiras entre diferentes tipos de produtos intelectuais e serviços informativo-culturais, e a suprimir as linhas divisórias entre comunicação privada e de massa, entre meios baseados em som e em vídeo, entre texto e vídeo, entre as imagens baseadas em emulsão e as eletrônicas, e mesmo a fronteira entre livro e tela. Uma das maiores conseqüências disso é a observável tendência de integração de diversos aspectos das políticas públicas para informática, eletrônica e telecomunicações, com alguns aspectos das políticas relativas aos mídia eà cultura. A Internet, aimprensa, a indústria gráfica, o rádio, a televisão, a biblioteca, 0 livro e as revistas científicas, as telecomunicações e a informática estão ficando maisinterconectadas e interdependentes, de tal forma que uma política de governo para uma delas pode ter significativas implicações para as outras. 
Em síntese, os elementos estruturais da Sociedade da Informação enfrentam hoje, entre outros, dois fortes condicionantes de natureza tanto conceitual quanto contextual: em primeiro lugar, uma retirada progressiva do estado, em benefício do espaço privado e mercantil, facilitando a acumulação de capital e a mercantilização dos espaços informacionais e culturais; em segundo lugar, uma instrumentalização direta das ações públicas em favor dos grupos empresariais, que pode trazer prejuízo do interesse público e da democratização dos serviços informativo-culturais.

É importante ressaltar que as formas de atuação do Estado com relação aos elementos estruturais da Sociedade da Informação são cruciais, uma vez que suas políticas podem traçar o horizonte e definir os modos de interação dos indivíduos, grupos, organizações e instituições públicas e privadas, tanto no interior do Estado quanto fora de seus limites institucionais. Foram as políticas seguidas pelos estados nações do mundo ocidental que levaram, contemporaneamente, o conhecimento e a informação a serem crescentemente apropriados como mercadorias para venda e lucro. É da mesma fonte, portanto, ainda que sustentada por uma sociedade civil, de dimensões nacional e multinacional, que deverão sair as estratégias e caminhos para a democratização da informação.

Independentemente dos caminhos que adotemos na determinação das políticas públicas que nortearão a implantação da Sociedade da Informação no Brasil, caberia levar em consideração os seguintes conceitos na abordagem do tema:

a) a imprevisibilidade dos caminhos que a inteligência humana fará destes elementos estruturais seguir. 0 vertiginoso desenvolvimento das tecnologias de informação e comunicações tem sido um poderoso instrumento para a rotinização, reorganização e automatização do trabalho intelectual. 0 fenômeno tecnológico tem operado como liberador de energia cognitiva, que será necessariamente aplicada na área de conhecimento de cada ser humano, não importa seu nível de educação. E dado que além de liberar energia o fenômeno tecnológico também disponibiliza um fantástico arsenal de ferramentas de concepção e desenvolvimento de produtos e processos, toma-se impossível prever os conteúdos em si mesmos e, mais que isto, as formas que tais conteúdos tomarão, e a ma neira como os elementos estruturais se organizarão e se relacionarão entre si e com os consumidores.

b) a incontrolabilidade dos conteúdos que circulam, sob várias formas, através dos serviços de informações e comunicações. $E$ ' da própria natureza dos elementos estruturais da Sociedade da Informação, sobretudo pelo avanço extraordinário da convergência tecnológica entre informática, comunicações e eletrônica, a incontrolabilidade da produção e circulação de conhecimento. 0 desenvolvimento tecnológico equilibra a equação social inventando dispositivos de relativo controle de consumo, pelo menos enquanto se necessita de máquinas lógicas para acessar o conhecimento circulante. Mais importante que isto, contudo, éo fato incontestável de a incontrolabilidade da produção ecirculação do conhecimento ser parte constitutiva, estruturante mesmo, da cultura contemporânea. 
Ela, através das tecnologias de informação e comunicações, realiza e radicaliza o sonho humano libertário.

c) a inevitabilidade de ação pública no setor, seja regulando - ou desregulando? - ou re-regulando? - a organização, a gestão e a produção, na intenção de garantir 0 atendimento do interesse público, a ordem democrática, os valores morais e éticos, a livre competição e a busca contínua da universalização do consumo dos serviços de informação e comunicações. Isto leva o Programa Sociedade da Informação, necessariamente, a conceber-se como parte e não todo, no sentido de que somente poderá se realizar, enquanto programa de governo, se estiver afinado com os propósitos, ações e missões das instâncias de governo e agências reguladoras que interferem nos setores de informação e comunicações. As políticas que tenham sido ou forem traçadas para cada um destes setores condicionarão, inevitavelmente, se não todas, parte substancial das diretrizes e ações que se estabeleçam para o Programa.

d) a indutibilidade necessária, por parte do govemo, de preferência indiretamente (por intermédio de agências específicas, democraticamente instituídas), no sentido de encorajar e fomentar a produção de conteúdos que dinamizem, fortaleçam, preservem e globalizem as identidades e as culturas nacionais. Não se trata, evidentemente, de ação indutora imposta, mas sim resultante de diálogo aberto, pelo qual se possa identificar e priorizar o que e como atender as várias nuances de nacionalidade, inclusive como meio de sedimentação da nacionalidade como um todo. 0 mercado livre, globalizado, é uma força cujo direcionamento no interior de cada país, se faz de acordo com as possibilidades maiores de lucro rápido e vultoso. A uniformidade e a banalização dos valores culturais, sua reinterpretação pela via mercantil e a simplificação de suas complexas, históricas e ricas articulações internas e externas são conseqüências esperadas - ejá constatadas - da ação deste mercado falsamente livre, subordinado à economia global. A indução de programas e projetos de ação, e o envolvimento neles dos sistemas formais e não-formais de educação, organizações sociais e culturais de atuação local, será fator crucial para tornar a(s) cultura(s) brasileira(s) capaz de dialogar com o global e dele se beneficiar.

\section{OS CONTEÚ DOS E A SOCIEDADE DA INFORMAÇÃO NO BRASIL}

Um dos principais indicadores do desenvolvimento da sociedade da informação é a penetrabilidade ou capilaridade das tecnologias de informação na vida diária das pessoas e no funcionamento e transformação da sociedade como um todo. Em âmbito geográfico, a penetrabilidadeé medida principalmente pelo número de usuários da Internet em uma determinada população. No caso do Brasil, estima-se que durante 0 ano 2000 mais de 6 milhões de brasileiros serão usuários da Internet e que nos próximos cinco anos poderemos chegar a 30 milhões. Estas cifras, apesar de muito aquém do total da população brasileira ou das porcentagens de usuários rela- 
tivas ao total das populações nos países desenvolvidos, constituem indicadores significativos do enorme impacto que a Internet está promovendo na sociedade brasileira. Em termos numéricos, estas cifras projetam o Brasil como um dos grandes mercados nacionais da Internet em nível mundial.

O utro indicador fundamental da sociedade da informação, que complementa a penetrabilidade das tecnologias de informação, constitui o nível de operação ubíqua, em um determinado contexto, de recursos, produtos e serviços de informação na Internet por parte dos seus usuários, representando indivíduos, governos e as mais diferentes organizações sociais de caráter público ou privado. Esta operação ubíqua representa a consecução de inovações muitas vezes radicais no funcionamento da sociedade atual, especialmente nas atividades e processos que requerem 0 acesso à informação.

Na sociedade dainformação, a comunicação ea informação tendem a permear as atividades e os processos de decisão nas diferentes esferas da sociedade, incluindo a superestrutura política, os governos federal, estaduais e municipais, a cultura e as artes, a ciência e a tecnologia, a educação em todas as suas instâncias, a saúde, a indústria, as finanças, o comércio e a agricultura, a proteção do meio ambiente, as associações comunitárias, as sociedades profissionais, sindicatos, as manifestações populares, as minorias, as religiões, os esportes, lazer, hobbyes, etc.. A sociedade passa progressivamente a funcionar em rede. 0 fenômeno que melhor caracteriza esse novo funcionamento em rede é a convergência progressiva que ocorre entre produtores, intermediários e usuários em torno a recursos, produtos e serviços de informação afins.

O s recursos, produtos e serviços de informação são identificados na Internet com o nome genérico deconteúdos. Em resumo, conteúdo étudo o queé operado na Internet. Uma das contribuições mais extraordinárias da Internet é permitir que qualquer usuário, em caráter individual ou institucional, possa vir a ser produtor, intermediário e usuário de conteúdos. E o alcance dos conteúdos é universal, resguardadas as barreias lingüísticas e tecnológicas do processo de difusão. É através da operação de redes de conteúdos de forma generalizada que a so ciedade atual vai mover-se para a sociedade da informação. A força motriz para a formação e disseminação destas redes reside na eficiência das decisões coletivas e individuais. O s conteúdos são portanto o meio e o fim da gestão da informação, do conhecimento edo aprendizado na sociedade da informação.

Resumindo, a sociedade da informação desenvolve-se através da operação de conteúdos sobre a infra-estrutura de conectividade. Portanto, o desenvolvimento da sociedade da informação no Brasil requer no futuro próximo um esforço nacional conjugado para aumentar, por um lado, a penetrabilidade da Internet pari passucom o uso adequado de tecnologias da informação (incluindo os softwares potentes e amigáveis, com ergonomicidade) e, por outro lado, o volume de conteúdos basileiros. Nesse sentido, é de esperar-se que, a partir de um determinado momento do futuro, a interconectividade expressada através da penetrabilidade das tecnologias deinformação con- 
vergindo na Internet, será realizada como uma necessidade sócio-econômica de operar conteúdos. Em outras palavras, a operação de conteúdos constitui o elemento estratégico nas políticas e programas de promoção da sociedade dainformação.

Entretanto, a Internet é dominada pelos conteúdos gerados nos países desenvolvidos. É mesmo aceitável dizer que os indicadores de volume de conteúdos operados por um país na Internet, medidos com relação ao seu Produto Interno Bruto ea sua População, é proporcional ao seu grau de desenvolvimento econômico e social. Mas é justo reconhecer que a questão não é apenas quantitativa, na acepção simplista de que a um maior volume de exposição ou de produção própria de conteúdos necessariamente corresponderia a um maior e mais rápidos índices de desenvolvimento social porque este requer abordagens mais sofisticadas de interpretação. Incluindo aí as análises relativas a acessibilidadex uso, custo-benefício eníveis de sa tisfação de usuários versus disponibilidade.

D eve-se ressaltar aimportância do processo de seleção de conteúdos e dos níveis de qualidade relativa (no sentido interpessoal) que deverá ser objeto de análise e controle por parte dos sistemas intermediadores de informação, mediante instrumentos adequados nas etapas de formação de estoques, processamento técnico e disseminação. D a ação normalizadora e do tratamento parametrizado dos conteúdos vai depender sua melhor difusão e uso pela sociedade.

Podemosir mais além e prever que será o volume de conteúdos operados por um país que determinará o seu desenvolvimento econômico e social e a qualidade de vida de seus habitantes. Em um contexto globalizado, o volume de conteúdos operados por um país passa também a medir a sua capacidade de influenciar e de posicionar a sua população no futuro da sociedade humana.

Portanto, aumentar o número e a qualidade de conteúdos nacionais é uma demanda e um desafio enorme que o Brasil está enfrentando hoje não somente para assegurar a nossa presença futura na rede mundial mas principalmente para dotar a sociedade brasileira dos recursos, produtos e serviços de informação adequados às nossas necessidades e condições sociais, econômicas e culturais. Nesse sentido, 0 G overno Brasileiro, através do Programa Sociedade da Informação respondea esta demanda com a proposta de promover no futuro imediato um aumento radical na criação e operação de conteúdo nacionais na Internet, em um esforço conjunto das nossas instituições públicas e privadas e, particularmente, de um número crescente de iniciativas individuais.

D evemos reconhecer que a Sociedade da Informação, em escala planetária, e de forma acelerada, vem desenvolvendo gigantescos estoques informacionais sobre os mais variados temas, em diferentes formatos, para todos os públicos, principalmente nos países mais avançados.

Esse inestimável repertório permite tanto o compartilhamento deconhecimentos, informações e dados quanto promove o desenvolvimento do capital humano e os princípios da solidariedade entre os povos. 
Mas também pode acarretar em alienação dos valores locais, o que vem motivando os governos e as sociedades de quase todos os países à adoção de estratégias para promover a produção e a difusão de estoques de informações nacionais e/ ou regionais, como já foi argumentado. Resumindo, a sociedade se organiza em torno de uma cultura, que é uma maneira de ver o mundo, através de um conjunto de idéias implícitas e explícitas, que acabam predominando entre as possíveis.

O conceito de identidade cultural impõe-se nesse contexto, o que implica também na noção dosconteúdos desejáveis enecessários no (pretendido) processo de informatização/ socialização.

\section{CONTEÚDO E IDENTIDADE CULTURAL}

As concepções de identidade cultural vêm transformando-se ao longo do processo civilizatório. D esde aquele sujeito do Iluminismo entendido como totalmente unificado desde seu nascimento, dotado das capacidades de razão, consciência e ação, passando pela idéia mais recente do "sujeito sociológico" que se forma nas relações com outras pessoas que mediam seus valores, sentidos e símbolos expressos numa cultura. Em tal acepção, projetamos a nós próprios nessas identidades culturais, na medida em que internalizamos tais significados e valores, alinhando nossos sentimentos subjetivos com os lugares objetivos que ocupamos no mundo social e cultural em que vivemos. O u seja, o mundo exterior é que estaria mudando, fragmentando 0 indivíduo, obrigando-o a assumir várias identidades. Com o agravante de que 0 ambiente em que vivemos agora é considerado provisório e variável.

O sujetopósmodemo, consequentemente, não tem uma identidade fixa, essencial ou permanente, já que está sujeito a formações e transformações contínuas em relação às formas em que os sistemas culturais o condicionam.

Em outras palavras, o sujeito pós-moderno é definido historicamente e não mais biologicamente - como preferem os que defendem identidades raciais originais mas sem bases científicas - , porquanto o sujeito assume identidades diferentes em diferentes momentos, afetadas tanto pelos processos de socialização quanto de globalização dos meios de comunicação e informação. A sociedade em que vive o sujeito não é um todo unificado e monolítico, uma totalidade, que flui e evolui a partir de si mesma, pois está também constantemente sendo descentrada e deslocada por forças externas.

Também é válido ressaltar que as identidades são contraditórias e que as pessoas participam de várias simultaneamente, em combinações às vezes conflitantes tais como ser mulher, pobre, homossexual e negra a um mesmo tempo. Vale também dizer que essa identidade muda com a forma como o sujeito é interpelado ou representado e que sua identificação nem sempre é automática, que ela precisa ser conquistada e que pode ser alienada politicamente.

Já foi dito com muita propriedade que em vez de se falar de identidade como uma coisa acabada, deveríamos falar de uma idantificação de um processo e que essa 
identidade nunca éplena dentro dos indivíduos, ao contrário, ela precisa ser “preenchida" e desenvolvida.

As identidades nacionais não são nem genéticas nem hereditárias, ao contrário, são formadas e transformadas no interior de uma representação. Uma nação é, nesse processo formador de uma identidade, uma comunidade simbólica num sistema de representação cultural. E a cultura nacional é um disarso ou modo de construir sentidos que influenciam e organizam tanto as ações quanto as concepções que temos de nós mesmos.

Não é ocioso lembrar que taisidentidades, no caso do Brasil, estão embutidos em nossa língua e em nossos sistemas culturais mas estão longe de uma homogeneidade - que já não perseguimos-; ao contrário, estão influenciadas (as identidades) pelas nossas diferenças étnicas, pelas desigualdades sociais e regionais, pelos desenvolvimentos históricos diferenciados, naquilo que denominamos "unidade na diversidade". Como todas as nações, mas bem mais do que a maioria delas, somos híbridos culturais e vemos esse processo como um fator de potencialização de nossas faculdades criativas.

A Sociedade da Informação pretende ser uma dessas forças unificadoras e transformadoras, num contexto globalizante.

A globalização é um processo desigual que, em certa medida, pode ser considerado como a ocidentalização dos valores culturais de nossos tempos. Mas, paradoxalmente, a globalização vem fortalecendo a proliferação de identidades locais e, ainda que pareça utópico, a Sociedade da Informação que estamos ajudando a construir, também pode dar espaço para culturas geograficamente isoladas - como é, em parte, 0 nosso caso.

Seriajusto afirmar que os povos modernos vivem a dialética da tradiçãoe datradurãa em que persiste na conservação de suas raízes ao mesmo tempo que busca a transferência de sistemas simbólicos (de umas regiões para outras e também do exterior) que permitam acelerar seu próprio desenvolvimento social e cultural. O u seja - e este parece ser o caso brasileiro - as culturas híbridas (sincréticas?) constituem um dos diversos tipos de identidade de novo tipo que estão surgindo na pós-modernidade.

0 processo de globalização instrumentalizado pela troca acelerada da informação através dos novosmedia, que abolem as distâncias e o tempo, não têm provocado a homegeneização completa das culturas e das identidades. Pelo contrário, não apenas antigas querelas identitárias se mantêm vivas como multiplicam-se diferentes bolsões de identidades locais, de inspiração religiosa, étnica ou comportamental, reanimadas e fomentadas como maneira de resistir à introdução de novos modos identitários uniformizantes. A tendência para a cristalização e difusão de uma ou de algumas poucas linhas de força de alcance global surge como mais nítida no campo da economia do que no campo da cultura.

E sse quadro relativo à identidade cultural não se manifesta apenas no chamado mundo subdesenvolvido ou em desenvolvimento. Países do primeiro mundo vêem na preservação da identidade nacional o instrumento decisivo para autoca- 
pacitação não apenas em assuntos culturais como científicos e tecnológicos, com suas claras dimensões econômicas. Medidas de exceção são formuladas para proteger a cultura local em suas mais variadas formas e, mais que isso, é resguardado 0 próprio idioma nacional, que condensa uma visão de mundo específica - aquela supostamente mais adequada a dar conta de um determinado modo de vida, com seus valores e significados.

Assim, no momento em que o Brasil cuida de criar as condições para sua plena inserção na nova sociedade da informação, é vital que se estabeleça uma política que não se preocupe apenas com a questão econômica e tecnológica dos meios eletrônicos, em particular a Internet, mas que se volte também para os interesses das identidades culturais do país, que constituem seu software mais precioso e livre de direitos autorais.

Levando em consideração, portanto, que será necessário planejar as ações que conduzem à produção e distribuição de conteúdos que sirvam aos interesses da identidades culturais do país, eentendendo poridentidade cultural a soma de significados que estruturem a vida de um indivíduo ou de um povo, parte-se do princípio de que será necessário ter em mente, antes de mais nada, que a identidade cultural não é mais una porém múltipla.

Há, sem dúvida, uma identidade primária em vigor no país, representada pela língua natural aqui usada e que no caso do Brasil é de fato considerada una e unificadora. O s diferentes modos de falar não constituem barreira séria ao entendimento entre a população e não há, sob esse aspecto, reivindicações identitárias particularizantes. Isso não significa que a fonte de identidade primária do país não deva ser objeto de uma política cultural de apoio pensada para o novo sistema eletrônico de produção da informação. Pelo contrário. Programas específicos devem ser apoiados visando a consolidação do português como idioma privilegiado da sociedade de informação brasileira.

Já quando se trata das identidades secundárias (própria, como exemplo, de regionalismos e grupos de preferências de diversa natureza) o quadro se altera. Será necessário atentar para o fato de que ao lado daidentidade instituída (a identidade "oficial", quevem de cima para baixo e legitima a priori as existências e as propostas, que fornece o padrão ou código geral) manifestam-se diversas identidades instituintes que vêem de baixo para cima e, nesse impulso, conformam o indivíduo, 0 grupo e a comunidade. Entre essas identidades instituintes, duas chamam a atenção desde logo. D e um lado, as deresistência, próprias de minorias étnicas e religiosas, e que não raro se alimentam da memória ou do culto das origens. E de outro, as identidades instituintes de projeto, que podem dizer respeito também a minorias étnicas e religiosas mas que incluem outros grupos (de defesa da condição feminina ou da ecologia), entre os quais se incluem o dos produtores culturais, que se definem não pelo culto do passado mas pela idéia de um futuro organizado e que visam não apenas conservar-se num determinado estado como também propor novos modos 
de vida e novas visões de mundo para si e para a comunidade - numa palavra, que buscam a transformação da estrutura social.

Ao planejar sua entrada na sociedade dainformação, o país deverálevar em conta a questão da identidade cultural nessas suas várias manifestações e, de modo especial, não incorrer no equívoco - já observado no passado - de privilegiar apenas as formas identitárias definidas pelo culto da memória ou das origens. Na nova era cultural que se inicia, tão ou mais importante que a identidade vinculada ao passado éa identidade que se projeta para o futuro: é dela que provavelmente virão as respostas aos novos desafios e é ela que deve merecer particular atenção. O s efeitos práticos dessa distinção revelam-se desde logo. Q uando se pensar, por exemplo, nas maneiras de propiciar a constituição de redes digitais de museus será preciso levar em conta que os museus são por excelência os depositários da identidade instituída, aquela que já se cristalizou, que goza de um consenso forjado nas instituições culturais do país (escolas, imprensa, etc.). Ao lado dos museus existem, porém, alternativas especiais que devem ser contempladas por uma política para a informação de modo a dar espaço a identidades instituintes emergentes.

$\mathrm{O}$ adequado equacionamento do jogo identitário no momento em que se intensifica o processo de globalização será vital não apenas para convivialidade e o florescimento potencial criativo dos indivíduos e grupos como, de maneira ainda mais acentuada, para a capacidade de govemo nacional na sociedade da informação. Sem ela, não haverá condições de participação na conversa cultural, econômica, tecnológica e científica que se esboça na dimensão mundial. Q uando falta um interlocutor, o que prevalece é o discurso da imposição. 0 amparo às identidades culturais nos novos meios eletrônicos terá como resultado benefícios evidentes, jáconfigurados em países que avançaram nesse campo, na forma de incremento da atividade econômica em geral (novos empregos, maior arrecadação de impostos) e desenvolvimento da cidadania (com reflexos diretos sobre o grau de violência urbana). Estes são componentes da capacidade de govemo de forma geral, meta por excelência da consciência política de um povo. E, de todo modo, etapa inevitável no processo eventual de integração em blocos - primeiro regionais e, depois, mais largos - se se pretender que essa integração se faça com o respeito às exigências e potencialidades de um povo.

\section{OS PRODUTORES, INTERMEDIÁRIOSE USUÁRIOS DAS REDES DE CONTEÚDOS}

O desenvolvimento de conteúdos na Internet brasileira deverá cobrir ao longo dos próximos anos todas as instâncias e atividade sociais, na medida que o governo, as organizações sociais de caráter público e privado assim como comunidades e indivíduos passem a operar na Internet suas demandas e ofertas de informação. É através do uso ubíquo dos conteúdos em rede, a sua produção, inovação, veiculação 
e intermediação no dia a dia das instituições e dos indivíduos que a so ciedade da informação vai se conformando.

O aumento da importância econômica que a Internet brasileira vem adquirindo sinaliza queainiciativaprivada, com capital nacional einternacional, fará grandes investimentos no futuro próximo para mover a operação dos processos de geração de valor e de comercialização na Internet. Em conseqüência, haverá um aumento extraordinário de conteúdos brasileiros relacionados diretamente com as atividades econômicas, comerciais, sociais, culturais e de lazer, comandadas com fins de lucro pela iniciativa privada, incluindo os sítios de comércio eletrônico, investimentos, leilões, sítios institucionais, etc. Em particular, velhas e novas empresas ligadas à comunicação e ao lazer investirão em conteúdos de grande popularidade ou orientados a segmentos de públicos específicos em busca da formação de comunidades de usuários que alavanquem retornos econômicos futuros, como são, por exemplo, os portais genéricos e os orientados a públicos específicos, televisões, rádios, jornais, revistas populares, etc. A presença ativa das empresas privadas na Internet torna-se progressivamente vital para a sua sustentabilidade e posicionamento no mercado futuro. Este movimento contribuirá para um extraordinário aumento da penetrabilidade da Internet no Brasil, do número de usuários e de conteúdos.

Por outro lado, instituições de caráter público governamentais e não governamentais em todas as áreas são chamadas a operar na Internet conteúdos relacionados direta e indiretamente com o fortalecimento da presença e integração do Brasil no concerto das nações como são a governança, 0 aperfeiçoamento da democracia e da equidade so cial, a cidadania, a preservação e o desenvolvimento de nossa cultura ehistória, o fomento ao desenvolvimento econômico, a proteção ao meio ambiente, o fomento à pesquisa científica nacional e a ampla comunicação dos seus resultados, a melhoria da saúde, da educação e, em geral, da qualidade de vida dos brasileiros.

O s conteúdos dos governos federal, estaduais e municipais deverão progressivamentefacilitaro exercício dos direitos dos cidadãos assim como o cumprimento dos deveres públicos das instituições e dosindivíduos com vistas a promover uma transparência progressiva na governança.

As instituições ligadas à pesquisa científica, à tecnologia, à educação e à a saúde, deverão operar através da Internet a geração e comunicação de conhecimento, a educação à distância e a promoção da saúde, de modo a contribuir decisivamente para a melhoria da qualidade de vida do brasileiro e ao aumento do chamado capital social do Brasil.

No que se refereà democratização do acesso àinformação eao conhecimento, os arquivos, as bibliotecas, os museus e os centros de documentação cumprirão um papel estratégico em duas grandes áreas de atuação. Na primeira, como instituições sociais com a missão e vocação de intermediação que viabilizarão o acesso público, gratuito e assistido aos conteúdos da Internet aos indivíduos e comunidades não conectadas. Este papel será especialmente requisitado nas próximas duas décadas quando a grande maioria da população brasileira continuará desconectada. $\mathrm{Na}$ 
segunda área de atuação, estas instituições replicarão na Internet, inovando a partir do conhecimento e experiência acumulada na função de operar coleções de conteúdos organizados segundo metodologias e padrões de seleção e qualidade visando 0 seu acesso democrático e a sua preservação para a as gerações futuras. Estas coleções devem incluir no futuro imediato o melhor da nossa produção cultural, científica e técnica. Note-se que este caráter de serviço público e de preservação não é objetivo da grande maioria dos sítios na Internet centrados na veiculação de conteúdos de interesse imediato. Neste sentido, o Brasil deve seguir o exemplo dos Estados Unidos da A mérica e dos países da Comunidade E uropéia que estão financiando a operação de conteúdos estratégicos através de instituições de caráter público.

Porúltimo, o indivíduo, o cidadão, o usuário, deve ocupar o papel central. É o indivíduo, sendo usuário, a razão última da grande maioria dos conteúdos e processos que se dão na Internet. Mas a Internet coloca o indivíduo no centro não somente como receptor passivo mas como agente ativo e determinante, livre de escolher 0 conteúdo, interagir com ele, independemente do espaço e do tempo em que se localizam o usuário e os conteúdos. Mais que isso, a Internet enriqueceu o papel do usuário, o indivíduo, do cidadão, dotando-o com o potencial e a capacidade de produtor e intermediário de conteúdos. Este fato é notável porque viabiliza a democratização da gestão e do acesso ao conhecimento e permite a realização plena do indivíduo e do cidadão enquanto ser cultural.

\section{QUEST ÕES COMPLEMENTARES}

A implantação e a manutenção de uma rede ampla de acesso e uso de conteúdos informacionais de todo tipo implica, necessariamente, em instituir salvaguardas e garantir direitos e deveres tanto de intermediários quanto de usuários. Para tanto, são imprescindíveis ações quanto à

a) responsabildade dos intermediários (distribuidores) ou produtores de conteúdos quanto à matéria incluída neles, isto é, permitir o monitoramento da informação que disponibilizam sob o ângulo das atividades ilícitas por ventura envolvidas;

b) medidas de proteção de dados (incluindo dados sobre os usuários, privacidade e outras garantias);

c) medidas de proteção de direitos autorais (tanto medidas legais, de caráter punitivo quanto os de ordem tecnológicosno sentido preventivo);

d) políticas públicas de taxação pelos serviços culturais prestados; e

e) proteção dos consumidores de informação cultural.

O princípio do "tudo paratodos" que animaa concepção da sociedade em rede, levaria duas orientações - aparentemente antagônicas - que, devidamente equacionadas, poderão constituir-se em forças complementares no processo civilizatório, a saber: 
recursos informacionais externos ao país, possibilitados pela globalização dos meios de comunicação e pela telemática, podem ser utilizados como insums fundamentais para a capacitação, a atualização, a solução de problemas e para a recreação, ou seja, poderão ser transformados em oportunidades e em utilidades para as pessoal, em escala exponencial e inesgotável, constantemente atualizável.

O perigo da feudalização dos meios de comunicação e a veiculação de matérias incompatíveis com os princípios da dignidade humana só deverão ser tratados nos marcos dos foros internacionais competentes e no âmbito do estado de direito. Jamais mediante expedientes como a censura, o xenofobismo e outros preconceitos, considerando-se o ideal do livre acesso á informação um direito humano inalienável. Em suma, colocar o país nas correntes do saber universal, através do compartilhamento do patrimônio cultural da humanidade, apesar das limitações e barreiras existentes, ampliando a capacidade de tolerância e de respeito entre os povos eas nações.

* os recursos de infomação produzidos no país, pretéritos e contemporâneos, requerem um tratamento técnico privilegiado para garantir sua disponibilidade e acessibilidade a todos os níveis e em todos os lugares. É de interesse da sociedade brasileira acelerar o registro, o armazenamento e a promoção de dados, informações e conhecimentos sobre o país, nos níveis de governo, sociedade e indivíduos como geradores e produtores.

A existência de uma extensa e moderna infra-estrutura de acesso à informação, por si só, já desencadeia forças criativas e produtivas em escala considerável mas também requer estratégias adequadas para fomentar a melhor distribuição das oportunidades e a mais justa representatividade nacional, considerando as suas disparidades regionais.

Em conclusão para atingir-se tais objetivos sociais faze-se necessário, dentre os muitos pré-requisitos, a universalização do ensino formal e da educação continuada como condição de ingresso na sociedade do conhecimento e do aprendizado e, não menos importante, o treinamento massivo no uso das novas tecnologias interativas, de forma generalizada e em todos os níveis, como ferramenta de participação nas redes e sistemas. Este é o propósito que anima o Programa Sociedade da Informação no Brasil, como meio de promoção social, geração de empregos qualificados e melhoria da qualidade de vida. 


\section{BIBLIOGRAFIA MÍNIMA}

ARAUjo, Vânia Maria Rodrigues Hermes de; Freire, Isa Maria Freire. "Conhecimento para o desenvolvimento: reflexões para o profissional da informação". InformaçãoeSocialade: Estudos João Pessoa, vol. 9, no. 1, p. 61-75, 1999.

BARRETO, Aldo. "Mudança estrutural no fluxo do conhecimento: a comunicação eletrônica”. CiênaadaInfomação, vol. 27, n. 2, p. 122-127, maio/ ago . 1998.

CASTELls, Manuel. A sociedadeemrøe São Paulo: Paz e Terra, 1999. 3 v.

D ERTO UZOS, Michael. O queserá: comoonovommdbdainfomaçãotranformará nossasvidas. São Paulo: Companhia das Letras, 1997. 413 p.

FEATHER, John. Theinfomationsoidy, a study of continuityand dhange London: Library Association Publishing, 1994.

INFORMAÇÃO E GLOBALIZAÇÃO NA ERA DO CONHECIMENTO / Helena Maria Martins Lastres, SaritaAlbagli (organizadoras). Rio de Janeiro: Campus, 1999. $318 \mathrm{p}$.

LAMB, Roberta. "Informational imperatives and socially mediated relationships". Theinfomation socity, v. 12, p. 17-37, 1996.

LÉVY , Pierre. Asteendogjasdainfomação, ofuturodopensamentona eradainformática. Rio de Janeiro: Ed. 34, 1993. 208 p.

MASUD A, Y oneji. A sociøladedainformaçãocomosociedadepósindustrial. Rio de Ja neiro: Ed. Rio, 1983.. 312 p.

MCT/ CNPq/ IBICT. Basespara oBrasil na ScciedadedaInfomaçãa concitos, fundamentos e universo político da indústria e serviçes de contéda Brasília: CNPq/ Ibict; São Paulo: Inst. Uniemp, 1998. 164. (http:/ / www.ibict.br/ bibvirtu/ socinfo )

MiRANDA, Antonio. "G lobalización y sistemas de información: nuevos paradigmas y nuevos desafios". In : LaEducacoónSuperiorend sigoXXI:visiónde Améica Latina ye Caribe Tomo I. Caracas: UNESCO/ CRESALC, 1997. P. 1009-1022.

MorAES, D ênis de. Plandamídia; tendêniasda commicaçãonaeagddbal. Campo Grande: Letra Livre, 1998. 287 p.

POPPER, Karl R. "Três pontos de vista sobre o conhecimento humano".In: Conjeturas erfutaçós Brasíl;ia: Editora UnB, 1994. P. 125-146.

UNESCO. Wodd infomation report 1997/ 1998. Paris: Unesco Publishing, 1997. 390 p.

VILCHES, Lorenzo. Gldbalizaçãa, mídiaealturacontemparâne Campo G rande: Letra Viva, 1997. 237 p.

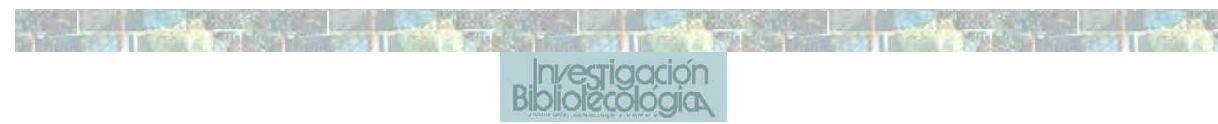

